\title{
Quality of Life of Patients with Non-melanoma Skin Cancers and their First-degree Relatives in Shiraz, Southern Iran: A Cross- sectional Study
}

\section{Nasrin Saki}

Shiraz University of Medical Sciences

\section{Maryam Mashhadi Nezhad}

Shiraz University of Medical Sciences

\section{Hengameh Kasraei}

Shiraz University of Medical Sciences

\section{Maryam Rezaee}

Shiraz University of Medical Sciences

\section{Negin Fazelzadeh Haghighi}

Shiraz University of Medical Sciences

Mohammad Mahdi Parvizi ( $\sim$ mmparvizi@gmail.com )

Molecular Dermatology Research Center, Shiraz University of Medical Sciences https://orcid.org/0000-0003-1856-945X

\section{Research}

Keywords: Quality of Life, skin neoplasms, squamous cell carcinoma, basal cell carcinoma

Posted Date: October 13th, 2020

DOI: https://doi.org/10.21203/rs.3.rs-89436/v1

License: @ (1) This work is licensed under a Creative Commons Attribution 4.0 International License. Read Full License 


\section{Abstract}

Background: Skin cancer is the most common cancer in the world. The aim of this study was to evaluate the quality of life (QoL) of both patients with non-melanoma skin cancer and their relatives.

Methods: This is an analytical cross-sectional study on patients with non-melanoma skin cancer and their first-degree relatives referred to dermatology clinic of Faghihi Hospital, Shiraz, Iran, 2018. Accordingly, patients and one of their companions were considered as the study group. Their responses to the questionnaires of Dermatology Life Quality Index and Family Dermatology Life Quality Index were analyzed using SPSS software, version 18.

Results: The QoL of the patients enrolled in this study was relatively good. The mean of the QoL score for patients with non-melanoma skin cancer was $10.5 \pm 6.2$ for men and $13.2 \pm 7.2$ for women which showed a statistically significant difference $(P=0.027)$. In the patient's companion group, the mean of their QoL scores were $9.4 \pm 5.6$ in men and $10.9 \pm 6.0$ in women with no statistically significant difference $(P=0.149)$.In addition, the $Q$ oL in both groups were not related to the type of skin cancer, sex and family relations.

Conclusion: The results of this study showed that the overall QoL of the patients and their relatives was moderate. However, a plan for improving QoLs of both groups should be considered as a part of the illness management.

\section{Introduction}

According to American cancer association report, skin cancer is the most common cancer in the world (1). At least $40 \%$ of all types of cancer in the world are related to the skin. Particularly among people with fair skin complexion, this type of cancer is very common, which predominantly includes melanoma, squamous cell carcinoma, and basal cell carcinoma(2). Squamous cell carcinoma and basal cell carcinoma are classified as non-melanoma skin cancers (NMSC) and account for $95 \%$ of all skin cancer cases. About $80 \%$ of nonmelanoma skin cancers are basal cell carcinoma (BCC) and $20 \%$ are squamous cell carcinoma (SCC) (3).

Melanoma is the 15th most common cancer among men and women. The prevalence of both melanoma and non-melanoma has increased in the recent decades (4). In Iran, skin cancer is the most common type, and like other countries, its prevalence is increasing. The results of a study showed that between 2006 and 2010, 1448 cases of death secondary to skin cancer occurred in Iran (5). According to the latest statistics released by the World Health Organization (WHO), in 2017, deaths related to skin cancer in Iran were reported to be 405 cases (ranked 143rd in the world) (6).

In all skin malignancy cases, abnormal changes in the skin, complications of therapeutic procedures, and the risk of recurrence after treatment are amongst the factors that can affect the normal life of an individual and his/her close relatives (7).

Due to longer life span of patients with non-melanoma type of skin cancer than melanoma and its higher prevalence, the psychological effects of this disease on patients may be greater (8). Assessing the quality of life (QoL) is an important topic, when investigating chronic diseases, especially cancer. Multiple studies have evaluated various aspects of QoL of individuals with cancer $(9,10)$. The aim of this study was to assess the QoL of the patients with non-melanoma skin cancers and their first-degree relatives referred to Dermatology Clinic of Shahid Faghihi Hospital, Shiraz, Iran in 2018.

\section{Materials \& Methods}

\subsection{Study design, participants and sample size:}

This study is a descriptive-analytic cross-sectional study. The statistical population consisted of all patients with non-melanoma skin malignancies and their first degree companions who referred to dermatology clinic of Dermatology Clinic, Faghihi Hospital, Shiraz, Iran in 2018. Diagnosis of NMSC in patients was confirmed by skin biopsy. For each patient, one of his/her first degree companion was placed in the companions' group. The patient's first degree companion was a person who referred to the clinic and had enough information about the patient, and did not have any disease. The minimum sample size was calculated 70 individuals in each group (patients and their relatives) with considering a standard deviation of 6.4 , an alpha error of 0.05 and a power of $80 \%$. At the end of the study, a total of 122 patients and 122 companions were included in this study with convenience sampling. People who did not have the ability to speak were not included, due to their inability to complete the questionnaire. Also, incomplete questionnaires were not included in the study.

\subsection{Data collection and questionnaires:}


Age, sex, type of NMSC (BCC or SCC), and the familial relation of the patients with their companion were documented. In order to assess the patients' QoL, we used Dermatology Life Quality Index (DLQI) questionnaire. This questionnaire was used to evaluate the patient's companion. These two questionnaires consist of 10 questions each, which are scored in a Likert 4-point scale ( 0 means at all, $1=1$ low, $2=$ high and $3=$ very high). Finally, the overall score of the questionnaire was measured between 0 (normal life) and 30 (severe impairment in life). Higher scores indicate a lower QoL. The questions in these questionnaires cover six domains of emotion, daily activity, leisure, work and education, personal communication, and treatment.

In many previous studies in other countries including Iran, validity and reliability of these questionnaires have been proven. Cronbach's alpha coefficient for the DLQI questionnaire was 0.79 in Aghaei et al.'s study (9) and 0.87 for the FDLQI in Safizadeh et al.'s study (11). The quality of life index score was measured statistically by age, sex, type of cancer (BCC or SCC), and type of family relationship with their companion in both groups.

\subsection{Statistical analysis:}

Data were analyzed using descriptive statistics (frequency distribution, mean and standard deviation) and inferential statistics (independent t-test and ANOVA) by using SPSS software version 18.

\subsection{Ethical statements:}

This research was approved by Ethics Committee of Shiraz University of Medical Sciences (Ethics code: 1397.360). The patients were aware about the protocol of the study. Accordingly, the patients' information was recorded anonymous.

\section{Results}

Demographic data of the participants are shown in Table 1. One hundred and nine (89.3\%) patients had BCC and 13 (10.7\%) had SCC. The familial relation of the companion with the patient was as follows: patient's spouse, the patient's child and the sibling of the patient; $45(36.9 \%), 67(54.9 \%)$ and $10(8.2 \%)$ individual were allocated to the three groups, respectively.

The patients and their companions' responses to the questionnaires of quality of life were analyzed. The frequency and percentage of the patients' rated scores to 10 questions of the DLQI questionnaire is shown in Table 2. The frequency and percentage of the patient's companion scores given to the 10 questions of the FDLQI questionnaire is shown in Table 3.

The mean and standard deviation of the quality of life score for patients with non-melanoma skin cancer were $10.5 \pm 6.2$ in males and $13.2 \pm 7.2$ in females. The results of t-test showed that the mean loss of QoL in female patients was significantly higher than the male ones $(P=0.027)$. In the patient's companions group, the mean and standard deviation of their QoL scores were $9.4 \pm 5.6$ in males and $10.9 \pm 6.0$ in females. Independent t-test was used to compare the QoL in both groups, but there was no statistically significant difference $(P=0.149)$.

Pearson correlation test showed a positive significant relationship between $Q$ oL mean score and patients' age $(r=0.492, P<0.001)$. On the other hand, there was no significant relationship between mean score of QoL and mean age of the patients' companions using Pearson correlation test $(P=0.256)$.

Comparison of the mean scores of QoL in patients by Mann Whitney test showed that non-melanoma type of cancer (BCC or SCC) had no significant relationship with the QoL score $(P=0.165)$. Comparison of mean scores of $Q$ oL of patients' companions using Mann-Whitney test showed that non-melanoma type of cancer (BCC or SCC) had no statistically significant relationship with their QoL $(P=0.878)$.

Table 4 shows the QoL of patient's companion and the type of relationship with the patient. In order to do this, we used analysis of variance. The results showed that the relationship between these two variables was not significant and the QoL in the three subgroups was almost the same $(P=0.455)$. 
Table 1

Distribution of sex and age of the patients with non-melanoma skin cancer and their

\begin{tabular}{|lllll|}
\hline \multirow{2}{*}{ Group } & Sex & Frequency & Percentage & Age mean \pm SD (year) \\
\hline Patients & Male & 73 & 59.8 & $65.9 \pm 10.3$ \\
\cline { 2 - 4 } & Female & 49 & 40.2 & \\
\hline Patients' companion & Male & 109 & 89.3 & $46.5 \pm 11.4$ \\
\cline { 2 - 4 } & Female & 13 & 10.7 & \\
\hline
\end{tabular}

Table 2

Distribution of answers to quality of life questions in patients with non-melanoma skin cancer

\begin{tabular}{|c|c|c|c|c|c|c|c|c|c|}
\hline \multirow[t]{3}{*}{ NO } & \multirow[t]{3}{*}{ Questions } & \multicolumn{8}{|l|}{ Score } \\
\hline & & \multicolumn{2}{|l|}{0 (At all) } & \multicolumn{2}{|l|}{ 1(Low) } & \multicolumn{2}{|l|}{2 (High) } & \multicolumn{2}{|c|}{3 (Very high) } \\
\hline & & frequency & Percentage & frequency & percentage & frequency & percentage & frequency & percentage \\
\hline 1 & $\begin{array}{l}\text { The } \\
\text { inconvenience } \\
\text { and pain of the } \\
\text { patient during } \\
\text { last week }\end{array}$ & 17 & 13.9 & 39 & 32.0 & 37 & 30.3 & 29 & 23.8 \\
\hline 2 & $\begin{array}{l}\text { Embarrassment } \\
\text { or nervousness }\end{array}$ & 20 & 16.4 & 40 & 32.8 & 31 & 25.4 & 31 & 25.4 \\
\hline 3 & $\begin{array}{l}\text { Indoor or } \\
\text { outdoor daily } \\
\text { works }\end{array}$ & 26 & 21.3 & 44 & 36.1 & 33 & 27.0 & 19 & 15.6 \\
\hline 4 & Type of cloths & 27 & 22.1 & 44 & 36.1 & 31 & 25.4 & 20 & 16.4 \\
\hline 5 & $\begin{array}{l}\text { Social and } \\
\text { recreational } \\
\text { activity }\end{array}$ & 42 & 34.4 & 41 & 33.6 & 27 & 22.1 & 12 & 9.8 \\
\hline 6 & $\begin{array}{l}\text { Preventing } \\
\text { exercise }\end{array}$ & 56 & 45.9 & 45 & 36.9 & 14 & 11.5 & 7 & 5.7 \\
\hline 7 & $\begin{array}{l}\text { Working and } \\
\text { studying }\end{array}$ & 54 & 44.3 & 33 & 27.0 & 23 & 18.9 & 12 & 9.8 \\
\hline 8 & $\begin{array}{l}\text { Interpersonal } \\
\text { communication }\end{array}$ & 40 & 32.8 & 48 & 39.3 & 24 & 19.7 & 10 & 8.2 \\
\hline 9 & $\begin{array}{l}\text { Sexual } \\
\text { problems }\end{array}$ & 54 & 44.3 & 28 & 23.0 & 25 & 20.5 & 15 & 12.3 \\
\hline 10 & $\begin{array}{l}\text { Treatment } \\
\text { problems }\end{array}$ & 55 & 45.1 & 41 & 33.6 & 20 & 16.4 & 6 & 4.9 \\
\hline
\end{tabular}


Table 3

Distribution of responses to quality of life questions in non-melanoma skin cancer patients' companion

\begin{tabular}{|c|c|c|c|c|c|c|c|c|c|}
\hline \multirow[t]{3}{*}{ NO } & \multirow[t]{3}{*}{ Questions } & \multicolumn{8}{|l|}{ Score } \\
\hline & & \multicolumn{2}{|l|}{0 (At all) } & \multicolumn{2}{|l|}{ 1(Low) } & \multicolumn{2}{|l|}{2 (High) } & \multicolumn{2}{|c|}{3 (Very high) } \\
\hline & & frequency & percentage & frequency & percentage & frequency & percentage & frequency & percentage \\
\hline 1 & $\begin{array}{l}\text { Psychological } \\
\text { pressure }\end{array}$ & 49 & 40.2 & 38 & 31.1 & 14 & 11.5 & 21 & 17.2 \\
\hline 2 & $\begin{array}{l}\text { Physical well- } \\
\text { being }\end{array}$ & 31 & 25.4 & 53 & 43.4 & 29 & 23.8 & 9 & 7.4 \\
\hline 3 & $\begin{array}{l}\text { Personal and } \\
\text { interpersonal } \\
\text { relationships }\end{array}$ & 45 & 36.9 & 41 & 33.6 & 31 & 25.4 & 5 & 4.1 \\
\hline 4 & $\begin{array}{l}\text { Reaction of } \\
\text { others }\end{array}$ & 40 & 32.8 & 51 & 41.8 & 24 & 19.7 & 7 & 5.7 \\
\hline 5 & Social life & 40 & 32.8 & 40 & 32.8 & 37 & 30.3 & 5 & 4.1 \\
\hline 6 & Recreation & 41 & 32.6 & 50 & 41.0 & 30 & 24.6 & 1 & 0.8 \\
\hline 7 & $\begin{array}{l}\text { Spend time on } \\
\text { caring the } \\
\text { patient }\end{array}$ & 39 & 32.0 & 38 & 31.1 & 39 & 32.0 & 6 & 4.9 \\
\hline 8 & $\begin{array}{l}\text { Additional work } \\
\text { at home }\end{array}$ & 40 & 32.8 & 56 & 45.9 & 23 & 18.9 & 3 & 2.5 \\
\hline 9 & Job and study & 47 & 38.5 & 40 & 32.8 & 31 & 25.4 & 4 & 3.3 \\
\hline 10 & Costs & 32 & 26.2 & 41 & 33.6 & 46 & 37.7 & 3 & 2.5 \\
\hline
\end{tabular}

Table 4

Comparison of familial relation of patient's companion with quality of life of non-melanoma skin cancer patient's companion

\begin{tabular}{|llcl|}
\hline \multirow{2}{*}{ Familial relation } & \multicolumn{2}{c|}{ Quality of life score of patient's companion } & P-Value \\
\cline { 2 - 3 } & Mean & Standard deviation & \\
\cline { 1 - 3 } Spouse & 11.06 & 6.69 & 0.078 \\
Child & 9.83 & 5.35 & \\
\hline Sibling & 9.10 & 5.24 & \\
\hline
\end{tabular}

\section{Discussion}

Chronic illnesses can make some changes in daily life of the patients and their caregivers that may affect QOL of them in different aspects, such as the psychological health, social life, working or studying, and expenses (12). According to our study on patients' QOL, embarrassment or nervousness had a higher score among the questions that influenced the patients' QOL in contrast to inconvenience and pain that had lower scores. The most and least affected aspect of QOL in the patients' companion group were psychological pressure and physical wellbeing, respectively.

In the study of Abedini et al. on 1500 patients with NMSC, $77.9 \%$ were mens and $22.1 \%$ were womens. The mean and standard deviation of the participants' age were $64.6 \pm 12.5$ and the percentage of BCC and SCC in their study was 75\% and 15\%, respectively; also, 5\% of the patients had both SCC and BCC. The studied population of Abedini et al. in terms of sex distribution and age was similar to our study, but the percentage of BCC and SCC types was different, which could be due to the differences in the place of study and exposure to environmental factors (13).

According to the result of our study, there was no significant difference in the QoL of patients based on familial relations. This could indicate that the incidence of non-melanoma skin cancer affects the QoL of different family members at the same level. However, in other 
studies, the QoL of patients' family using NMSC was not compared with the type of relationship with the patient. Handjani et al. showed that among the relatives of patients with Pemphigus Vulgaris, the spouses had a significant decrease in FDLQI scores in comparison with the children's and siblings'(14).

According to Ghaderi et al. study on Alopecia Areata, the mean scores in mental health, social function, and general health in patients were lower than controls which were in line with the results of our study(15). The study of Nourpisheh et al. on skin leishmaniasis patients showed that the highest mean score of SF-36 questionnaire was in the domain of general health and the lowest was in social function of the patients. In addition, the mean score of DLQI in patients in their study was 13.7 units (16), which was in-line with the results showed in our study. This difference could be related to differences in the enrolled patients in both studies. The study of Mardani et al. on cancer patients revealed that the QoL of patients with cancer was related to their mental health, and cancer had affected various aspects of patients' life, which were strongly in line with the results of our assessment. According to their study, several domains of QoL had a significant correlation with mental health in patients with cancer. In this regard, the domain of physical performance had a significant correlation with anxiety, social dysfunction and depression. Moreover, they showed that the mental health domain of QoL had a significant correlation with Quasi-physical symptoms of mental health domain. Finally, they showed that there was a significant correlation with social functioning disorder of mental health (17), which was in line with the results of our assessment.

The study of Zeyghami et al. on the QoL of patients with cancer undergoing chemotherapy showed that there were significant differences between the mean score of dimensions of physical performance, role, and emotional status in before and after three times chemotherapy. But, there was no statistically significant difference between the mean of cognitive and social dimensions (18).

Soghi et al. demonstrated that Iranian patients with type 1 neurofibromatosis had a moderate QoL and low quality of emotion and performance (19). These findings can be used to provide better healthcare for these patients in order to improve their QoL, which was consistent with the results of our assessment.

Goldstein et al. revealed that women undergoing adjuvant treatment for the early stages of breast cancer reported $36 \%$ significant levels of depression or anxiety. In this study, disability had the highest score in the retired patients. Moreover, Women with fatigue, with or without accompanying mood disorders, expressed different patterns of functional state. In particular, $40 \%$ of patients with high fatigue reported significant problem in climbing the stairs. Furthermore, the results of their study showed a significant correlation between progressive fatigue after cancer with mood and psychological disorders (20).

In our study, the mean score of QoL in women was significantly higher than men. The study of Soghi et al. showed the QoL of Iranian patients with Type I neurofibromatosis was not statistically correlated with age and sex, but the association between the range of symptoms with age was statistically significant (16). But, this association was not in line with our study that these results could be related to the differences of demographic characteristics of participants in both studies. Ansarin et al.'s study revealed that the QoL in patients with skin disorders and QoL in individual without skin disorders had positive correlation with age and income (21), which was not consistent with the results of our study, and this difference could be due to the differences in the methods and participants in both studies. Nourpishe et al. demonstrated that the total score of QoL in patients with cutaneous leishmaniasis had a negative correlation age (13), which was consistent with the result of our study.

According to our study, there was no statistically significant differences between the QoL of patients' companion with the sex of patients. Moreover, our study showed that there was no statistically significant relationship between QoL of patients and the types of nonmelanoma cancer (BCC vs. SCC). This result was similar for relationship between QoL of patients' companions and types of skin cancer, too.

This study was performed on patients in only one dermatology clinic that it could be the most important limitation of our study was. So, it is suggested that future studies be carried out on patients as multicenter projects in more factors that they may related to QoL.

\section{Conclusion}

The results of this study showed that although the overall QoL of the patients with non-melanoma skin cancer was moderate, this index in the patients and their companion was not related to types of cancer, sex and family relations. Therefore, according to reduced overall quality of specific aspects of life in each person, improving quality of life of the patients and their caregivers should be considered as a part of the illness management.

\section{Declarations}




\section{Ethics approval and consent to participate}

This research was approved by Ethics Committee of Shiraz University of Medical Sciences (Ethics code: 1397.360). The patients were aware about the protocol of the study. Accordingly, the patients' information was recorded anonymous.

\section{Consent to publish}

Not applicable.

\section{Availability of data and materials}

The datasets used and/or analyzed during the current study are available from the corresponding author on reasonable request.

\section{Competing interests}

The authors declare that there was no conflict of interest.

\section{Funding}

This study was financially supported by a grant [grant No. 95-01-01-11488] from the Vice-Chancellery for Research of Shiraz University of Medical Sciences.

\section{Authors' Contributions}

Study concept and design: NS, MR, MMP; acquisition of data: NS, MMN, HK, MR,MMP; data analyses: NS, MMP; drafting of the manuscript: MMN, HK, MR; ; critical revision of the manuscript for important intellectual content: NS, MMP; study supervision: NS, MMP; final approval of the version to be submitted: NS, MMN,HK, MR, MMP

\section{Acknowledgments}

The present article was extracted from the thesis written by Maryam Mashhadi Nezhad, which was financially supported by the Shiraz University of Medical Sciences [grant No. 95-01-01-11488]. The researchers would like to sincerely thank the participants; without their collaboration, the production of this article would be impossible. The authors wish to thank Mr. H. Argasi at the Research Consultation Center (RCC) of Shiraz University of Medical Sciences for his invaluable assistance in editing this manuscript.

\section{References}

1. Wheless L, Black J, Alberg AJ. Nonmelanoma skin cancer and the risk of second primary cancers: a systematic review. Cancer Epidemiol Biomarkers Prev. 2010;19(7):1686-95.

2. Brown DG, Rao S, Weir TL, O’Malia J, Bazan M, Brown RJ, et al. Metabolomics and metabolic pathway networks from human colorectal cancers, adjacent mucosa, and stool. Cancer Metab. 2016;4(1):11.

3. Hershman DL, Lacchetti C, Dworkin RH, Lavoie Smith EM, Bleeker J, Cavaletti G, et al. Prevention and management of chemotherapyinduced peripheral neuropathy in survivors of adult cancers: American Society of Clinical Oncology clinical practice guideline. J Clin Oncol. 2014;32(18):1941-67.

4. Hearn R, Kerr A, Rahim K, Ferguson J, Dawe R. Incidence of skin cancers in 3867 patients treated with narrow-band ultraviolet B phototherapy. Br J Dermatol. 2008;159(4):931-5.

5. Pakzad R, Soltani S, Salehiniya H. Epidemiology and trend in skin cancer mortality in Iran. J Res Med Sci. 2015;20(9):921.

6. Linder LA, Christian BJ, editors. Nighttime sleep disruptions, the hospital care environment, and symptoms in elementary school-age children with cancer. Oncology nursing forum; 2012: NIH Public Access. 
7. Lehmann P. Methyl aminolaevulinate-photodynamic therapy: a review of clinical trials in the treatment of actinic keratoses and nonmelanoma skin cancer. Br J Dermatol. 2007;156(5):793-801.

8. Abbas M, Kalia S. Trends in non-melanoma skin cancer (basal cell carcinoma and squamous cell carcinoma) in Canada: a descriptive analysis of available data. J Cutan Med Surg. 2016;20(2):166-75.

9. Aghaei S, Moradi A, Ardekani GS. Impact of psoriasis on quality of life in Iran. Indian J Dermatol Venereol Leprol. 2009;75(2):220.

10. Parvizi Z, Sadati AK, Azarpira N, Parvizi MM, Tabrizi R, Heydari ST, et al. Study of quality of life among liver transplant candidates in Shiraz, Southwestern Iran. Galen Medical Journal. 2016;5(4):180-87.

11. Safizadeh H, Nakhaee N, Shamsi-Meymandi S, Pourdamghan N, Basra M. Preliminary reliability and validity of Persian version of the Family Dermatology Life Quality Index (FDLQI). Qual Life Res. 2014;23(3):869-75.

12. Sampogna F, Tabolli S, Di Pietro C, Castiglia D, Zambruno G, Abeni D. The evaluation of family impact of recessive dystrophic epidermolysis bullosa using the Italian version of the Family Dermatology Life Quality Index. J Eur Acad Dermatol Venereol. 2013;27(9):1151-5.

13. Abedini R, Nasimi M, Pour PN, Moghtadaie A, Tohidinik HR. Quality of life in patients with non-melanoma skin cancer: implications for healthcare education services and supports. J Cancer Educ. 2019;34(4):755-9.

14. Sajedianfard S, Handjani F, Saki N, Heiran A, Kardeh S, Jowkar F, et al. Family dermatology life quality index in patients with pemphigus vulgaris: A cross-sectional study. Indian J Dermatol Venereol Leprol. 2019.

15. Ghaderi R, Saadatjoo S, Khoshzaher S. Comparison Quality of life for patients with alopecia areata and healthy individuals. Journal of Birjand University of Medical Sciences. 2011;18(3):200-9.

16. Noorpisheh S, Naghizadeh MM, Nikrouz L. A study on the life quality of patients suffering from leishmaniasis. Journal of Fasa University of Medical Sciences. 2013;3(2):155-62.

17. Mardani Hamule M, Shahraki Vahed A. Relationship between mental health and quality of life in cancer patients. SSU_Journals. 2010;18(2):111-7.

18. Mohammedi SZ, Hushmand P, Kooshyar M. Quality of life in cancer patients undergoing chemotherapy. Scientific Journal of Hamadan Nursing \& Midwifery Faculty. 2008;16(1):5-15.

19. Soghi I, Saeedi S, Sanagoo A, Jouybari L, Ebrahimirad M, Mehravar F. Quality Of Life in a Group of Iranian Patients with Neurofibromatosis Type 1 with Cutaneous Expressions. Journal of Mazandaran University of Medical Sciences. 2018;28(162):95103.

20. Goldstein D, Bennett B, Friedlander M, Davenport T, Hickie I, Lloyd A. Fatigue states after cancer treatment occur both in association with, and independent of, mood disorder: a longitudinal study. BMC cancer. 2006;6(1):240.

21. Ansarin H, Kabir A, Mirishekarab A. Comparison of dermatologic patients quality of life with healthy people. Razi Journal of Medical Sciences. 2003;9(32):649-58. 